\title{
La Inquisició de València contra Vicent Navarro (1750-1757), Diego Ramírez (1742) i Pedro Navarro (1588), tres casos de bestialisme
}

\author{
The Inquisition of Valencia against Vicent Navarro (1750-1757), Diego \\ Ramírez (1742) and Pedro Navarro (1588), three cases of bestiality
}

\author{
Jacob Mompó Navarro \\ jacobmompo@gmail.com \\ Universitat Catòlica de València
}

\begin{abstract}
Resum: La sodomia i el bestialisme han estat considerats al llarg de l'edat mitjana i moderna com un dels màxims exponents del pecat de luxúria. El «crim nefand», entés com una ofensa directa a Déu, va ser perseguit per diversos corpus jurídics arreu de l'Europa cristiana, i els autors del «crim contra natura» sovint eren condemnats a la foguera. Tanmateix, pel que fa als processos que ací presentem, les penes amb què els acusats van porgar els seus crims van ser més benèvoles. Aquest és el cas de Vicent Navarro, que va commutar la pena capital per la de galeres; o Pedro Navarro, que va haver de patir el desterrament. Desconeixem la sentència de Diego Ramírez, per bé que, a més de bestialisme, va ser acusat també d'hermafroditisme i sodomia.
\end{abstract}

Paraules clau: bestialisme, sodomia, pecat nefand, crim contra natura, hermafroditisme

Abstract: Sodomy and bestiality have been considered throughout the Middle Ages and Modern Era as one of the greatest exponents of the sin of lust. The «ineffable crime», understood as a direct offense to God, was pursued by various judicial corpora throughout Christian Europe, and authors of the «crime against nature» were often condemned to the bonfire. However, regarding the processes we present here, the penalties the accused paid for their crimes became more benevolent than the death penalty. This is the case of Vicent Navarro, who exchanged capital punishment for galley penalty; or Pedro Navarro, who had to suffer from exile. We do not know the sentence of Diego Ramirez who, besides bestiality, was also accused of hermaphroditism and sodomy.

Keywords: bestiality, sodomy, ineffable sin, crime against nature, hermaphroditism

\footnotetext{
* Aquest article s'inclou en les recerques de l'equip de treball del projecte d'investigació «Biografías marginales: violencia, sexo, género e identidad. Edición y análisis de fuentes documentales valencianas de la Época Foral» (PGC2018-097011B-I00) del Ministerio de Ciencia, Innovación y Universidades del Gobierno de España.
}

DATA PRESENTACIÓ: 14/04/2019 ACCEPTACIÓ: 20/05/2019 • PUBLICACIÓ: 23/06/2019 
Jacob Mompó Navarro. La Inquisició de València contra Vicent Navarro (1750-1757), Diego

Ramírez (1742) i Pedro Navarro (1588), tres casos de bestialisme

\title{
1. Introducció
}

Per a la mentalitat cristiana occidental de l'edat mitjana i moderna, fortament influenciada per la tradició escolàstica, l'acte sexual tenia una finalitat exclusivament reproductiva. Qualsevol relació sexual encaminada, únicament, a l'obtenció de plaer, era considerada com un pecat. En aquest context va fer fortuna la classificació de fra Tomàs d'Aquino, que va dividir el pecat de luxúria en sis espècies, de més lleu a més greu: la fornicació, l'adulteri, l’incest, l'estupre, el rapte i el vici contra natura. ${ }^{1}$ Pel que fa a aquest darrer pecat contra natura, encara va dividir-lo en quatre subespècies més:

\begin{abstract}
El primero, el que procura la polución sin coito carnal, por puro placer, constituye el pecado de inmundicia, conocido también como molicie. El segundo, en el que el coito tiene lugar con un ser de distinta especie, se identificaba con la bestialidad. El tercero, si se realiza el coito con el sexo no debido, sea de varón con varón o de mujer con mujer, lo llamaban vicio sodomítico. El cuarto recogía los modos no naturales de realizar el coito, fuese porque se hacía con un instrumento no debido o porque se empleaban otras formas antinaturales (Montero 2010: 46).
\end{abstract}

Malgrat que totes aquestes accions pecaminoses eren considerades com un greu atemptat contra la voluntat divina, la sodomia i el bestialisme esdevenien els més greus dels pecats de luxúria, en tant que no es tractava, únicament, d'una «fornicació extramatrimonial», sinó una ofensa directa a Déu i a la creació divina (Motis 2000: 351). Al contrari del paper passiu que hom li pressuposava a la dona, l'home era el portador de la llavor de la procreació; malbaratar aquesta sement en relacions sexuals que no tenien la finalitat reproductiva esdevenia una ofensa al mateix Déu (Tomás y Valiente 1990: 35). Així doncs, malgrat que la sodomia i el bestialisme eren perseguits tant per la justícia seglar com per la religiosa, el motiu d'aquesta persecució derivava directament d'aquesta condició ofensiva envers Déu. Segons Masferrer:

\begin{abstract}
Algunos autores, entendiendo que esta conducta atentaba tan solo a la naturaleza («contra natura»y, por tanto, carente de víctima), y que la única persona ofendida era Dios (de ahí su denominación como «peccatus nefandus»), llegaron a la conclusión de que la sodomía se penalizó exclusivamente por constituir una ofensa a Dios, es decir, por tratarse de un pecado grave. De este modo la sodomía se ha convertido, según estos autores, en el ejemplo más paradigmático de la tesis que defiende la identificación entre delito y pecado en el Derecho penal medieval y moderno (Masferrer 2017: 720).
\end{abstract}

Per tant, la pràctica luxuriosa d'aquest «vici contra natura» convertia els acusats en criminals, al mateix temps que pecadors. ${ }^{2}$ Això no obstant, malgrat que la masturbació, des d'un punt de vista

1 Per a la descripció dels pecats de luxúria vegeu Tomás y Valiente (1990: 33-55). També són interessants l'apartat «Els marcs doctrinals» de Riera i Sans (2014: 24-41), el capítol «El concepto de pecado nefando» de Carrasco (1986: 30-50) i l'article de Montero (2010).

2 Per a l'evolució de la consideració de la sodomia com a pecat i delicte resulta interessant l'article de Molina (2010). En aquest mateix sentit, vegeu Masferrer (2017). D’altra banda, ja havíem fet referència, abans, a la dicotomia pecatdelicte existent en la societat medieval i moderna envers la sodomia i, per extensió, al bestialisme (Mompó 2018: 37-42).

SCRIPTA, Revista internacional de literatura i cultura medieval i moderna, núm. 13 / juny 2019 / pp. 139 - 158 ISSN: 2340-4841 · doi:10.7203/SCRIPTA.13.15478 
Jacob Mompó Navarro. La Inquisició de València contra Vicent Navarro (1750-1757), Diego Ramírez (1742) i Pedro Navarro (1588), tres casos de bestialisme

teològic i moral, també resultava una ofensa a Déu, no va ser generalment perseguida i, per tant, les lleis que punien aquest comportament igualment «contra natura», rarament s'aplicaren en la pràctica ni, molt menys, amb la mateixa eficàcia que amb la sodomia ${ }^{3}$ (Masferrer 2017: 720).

D’altra banda, per bé que la justícia regular -tant seglar com religiosa- perseguia la sodomia i el bestialisme des de l'edat mitjana, la Inquisició no va aconseguir jurisdicció plena sobre el «pecat nefand» fins a l'any 1524, gràcies al breu concedit per Climent VII; i únicament va gaudir d'aquesta jurisdicció la Inquisició dels territoris de la Corona d'Aragó ${ }^{4}$-exceptuant Mallorca-, però no a la resta de la Monarquia Hispànica (Bazán 2007: 437).

Pel que fa als territoris de la Corona d'Aragó, el crim «contra natura» ja era punit amb la mort, segons el corpus de lleis visigodes, vigents fins a l'any 1251, així com les antigues lleis imperials romanes, recollides a les diferents compilacions conegudes com el Corpus iuris civilis. En el cas concret del regne de València, Jaume I va concretar-ne la pena - mort a la foguera- amb un privilegi del 19 de febrer de 1251 (Riera i Sans 2014: 47). La mateixa sort patien els sodomites de Castella, on la punició del «vici contra natura» ja la recollien les Siete Partidas d'Alfons X (Abad \& Garcia 1999: 5). En qualsevol cas, totes les lleis aplicables tenien reservada la condemna a mort per als que cometien el «pecat nefand».

Ara bé, pel que fa al cas concret del bestialisme, sembla que, en la pràctica, va haver-hi inicialment certa tolerància pel que fa a l'aplicació de la pena capital; almenys, fins a la promulgació d'una pragmàtica, del 22 d'agost de 1497, pels Reis Catòlics, que instaurava la mort a la foguera per a qualsevol acusat de «pecat nefand». A tall d'exemple, el judici de la Real Chancilleria contra Juan de Atienza, resolt en juny d'aquell mateix any de 1497, va declarar l'acusat culpable del delicte de bestialisme. La condemna amb què es va punir el seu crim va ser una multa econòmica, cinquanta fuetades i el pagament de les costes del procés (Martínez Sanz 2016). En canvi, el procés contra Juan de la Liset, de 1662, va finalitzar amb la mort de l'acusat i de l'animal amb què va cometre el delicte:
El dicho pregonero y ejecutor de la justicia todo en un su efecto puso a cavallo en una bestia menor de alvarda al dicho Juan de la Liset y le ató a ella y le puso y bistió una ropa negra de bayeta y una gorra de lo mismo y le puso una soga al pescuezo y le sacó de la dicha carcel. Y a la puerta d'ella dio el primer pregón en la forma referida en altas e inteligibles boces, y fue por las calles públicas y acostumbradas d'esta villa pregonando el dicho delito a trechos asta que llegó [...] donde estaba puesto un palo, y en él le dio garrote y le aogó y murió naturalmente. Y después, el susodicho ejecutor de la justicia llevó leña donde estava el cadaver susodicho y la encendió, y se fue quemando poco a poco asta que totalmente todo el cuerpo fue echo polvos y ceniza que fue albelada por el aire. Y asimismo llevó lumbres y leña a la dicha borrica con

\footnotetext{
3 No hem de perdre de vista que el pecat-delicte de sodomia va ser igualment perseguit independentment del gènere dels seus practicants. Un estudi interessant sobre la sodomia femenina a Molina (2014). Per a l'evolució del discurs homofòbic a l'edat mitjana, vegeu l'obra de Bazán (2007).

4 Aquest fet explica que tots els casos de bestialisme estudiats a l'interessant treball de Ruiz Astiz (2017), focalitzat al regne de Navarra, foren jutjats per la justícia reial.
}

SCRIPTA, Revista internacional de literatura i cultura medieval i moderna, núm. 13 / juny 2019 / pp. 139 - 158 ISSN: 2340-4841 · doi:10.7203/SCRIPTA.13.15478 


\title{
Jacob Mompó Navarro. La Inquisició de València contra Vicent Navarro (1750-1757), Diego Ramírez (1742) i Pedro Navarro (1588), tres casos de bestialisme
}

\begin{abstract}
que se avia cometido el dicho delito, la qual avia ido juntamente con el dicho Juan de la Liset desde la dicha carcel por todas las calles públicas reatada con la bestia en que iba. Y estando en el mismo sitio de suplicio, el dicho executor de la justicia a la dicha borrica con un mazo de herrero un golpe en la cabeça y a segunda dándole otra le mató y la llebó la dicha leña a la dicha borrica y la encendió y quemó parte d'ella por la zeremonia (Abad \& García 1999: 14-15).
\end{abstract}

No obstant això, els processos que presentem en aquest treball no van ser jutjats per la justícia regular, sinó que van recaure en l'àmbit jurisdiccional del Tribunal de la Inquisició de València, que -recordem- sí que tenia jurisdicció plena sobre la sodomia i el bestialisme. D’altra banda, tret del procés contra Pedro Navarro (1588), els altres dos casos de bestialisme que incorporem ací es produïren a mitjan segle XviII, moment en què les penes contra el bestialisme ja s'havien suavitzat. Per contra, pel que fa al cas de Diego Ramírez (1742), per bé que desconeixem el resultat de la sentència, hem de tenir present que, a més de ser acusat de bestialisme, la seua causa contenia també acusacions sobre relacions sexuals mantingudes freqüentment amb altres homes.

En qualsevol cas, al llarg d'aquest treball donarem a conéixer tres processos inquisitorials -amb les seues particularitats- en què els seus malaurats protagonistes van ser acusats d'haver mantingut relacions sexuals amb diferents espècies d'animals. En primer lloc, el procés contra Vicent Navarro, natural d'Alfafar i resident a Polinyà, acusat de bestialisme amb una somera, una egua i una gossa perdiguera. En segon lloc, Diego Ramírez, nascut a Abanilla (Múrcia) i criat del marqués de Rafal i senyor de Molins, acusat a Oriola de bestialisme, sodomia i hermafroditisme. Finalment, Pedro Navarro, o Arbonés, de Terol, denunciat per un únic testimoni singular, per haver mantingut relacions sexuals amb una vaca.

\section{Vicent Navarro, acusat de bestialisme}

El 19 de febrer de 1750, el Tribunal de la Inquisició de València emetia l'ordre de detenció contra Vicent Navarro, acusat del delicte de bestialisme. ${ }^{5}$ Segons l'esmentat document, Navarro: "Ha cometido el enorme y abominable delito de bestialidad, comerciando carnalmente con brutos de diversas especies" (Img. 5). Pel que es desprén del seu procés, Vicent Navarro era natural d'Alfafar, però es va traslladar de menut, amb son pare, a Algemesí, on van llogar una casa a Isidre Hurtado, moliner d'aquesta localitat de la Ribera. En el moment dels fets, però, l'acusat residia a Polinyà, on treballava de criat a sou de Baptista Sala.

El procés contra Vicent Navarro s'inicià en algun moment anterior al 13 de febrer de 1750, quan Baptista Sala i el llaurador Josep Garcia explicaren a Sebastià Garcia, rector de Polinyà, certs comportaments de l'acusat, sospitosos d'atemptar contra la doctrina i la moral cristianes. Oïda la denúncia d'aquests dos veïns, mossén Sebastià Garcia envià una carta al senyor inquisidor Francisco

5 AHN, Inquisición, 5321, exp. 32. Els processos que presentem aquí estan disponibles en línia al web del Portal de archivos españoles (pares.mcu.es). Indiquem en cada casa, entre parèntesis, l'abreviatura Img. seguida del número de la imatge digitalitzada. 
Jacob Mompó Navarro. La Inquisició de València contra Vicent Navarro (1750-1757), Diego Ramírez (1742) i Pedro Navarro (1588), tres casos de bestialisme

Espinosa i Trebiño. El Tribunal de València va disposar que mossén Miquel Sans, prevere i notari de la Inquisició en la ciutat de Sueca, actuàs com a comissari del Sant Ofici i efectuàs les diligències oportunes. Una d'aquestes diligències fou la compareixença del rector de Polinyà, per esclarir si la carta, efectivament, la va remetre ell, i que comunicàs: "Quién le dio la referida noticia, quánto tiempo ha que pasó, qué personas lo vieron, [...] En qué sitio sucedió, quántas veces y con qué especie de bestias" (Img. 11). El 13 de febrer de 1750, doncs, mossén Sebastià Garcia va ratificar tot el que havia expressat a la seua carta. El mateix 13 de febrer va declarar Josep Garcia, segons el qual, en agost de l'any anterior, 1749:

\footnotetext{
Havia visto como Vicente Navarro [...] estava cometiendo el pecado de bestialidad con una yegua tordilla en la partida del camino de Alcira, término de Corbera, y que viendo una cosa tan fea, le dio un grito dissiendo: «Hombre de poca vergüenza y mal christiano, ¿qué haces, cometiendo tal infamia?» (Img. 13).
}

L'endemà, 14 de febrer, testificà Baptista Sala. Aquest, a la seua declaració, afirmava haver vist Navarro:

\begin{abstract}
En el pajar, arrodillado, y las partes vergonzosas del dicho criado arrimadas eo juntas a las de una perra de perdices, y que le paresió que estava cometiendo el pecado de bestialidad; de cuya vista quedó sobresaltado y suspenso y, aunque se retiró algun tanto, bolvió a mirar segunda ves para mayor seguridad de lo que havía visto. A tiempo que se avía levantado, y viendo el dicho Navarro a su amo, que era el dicho Sala, se quedó corrido y vergonzoso. Y entonces se tapó eo cubrió sus partes vergonzosas el dicho Navarro. Y el haver visto lo sobredicho, fue movido de sospecha y curiosidad para ver lo que hacía el criado en el pajar dónde estava la perra criando, porque los más días, después de comer, a mediodía, y a senar, a la noche, estava grandes ratos jugando con la perra, que lo oía el declarante desde la cosina y no bajava sin embargo de llamarle muchas veces su amo, lo que le dio motivo a subir con silencio para ver lo que hasía en el pajar (Img. 16).
\end{abstract}

Després de descobrir els actes pecaminosos de Vicent Navarro, Baptista Sala el va acomiadar:

$$
\begin{aligned}
& \text { disiéndole que en todos los días de su vida no bolviese a su casa ni mirase su puerta, porque } \\
& \text { pensava tener en su casa un hombre de bien y avía visto que era un grande pícaro y mal } \\
& \text { hombre; y se fue sin bolver respuesta alguna (Img. 17). }
\end{aligned}
$$

Amb aquests testimonis i la declaració d'oïdes del rector, el 19 de febrer, com hem dit, la Inquisició va emetre la seua ordre de detenció contra Vicent Navarro i la confiscació dels seus béns. L'encarregat d'aquesta operació va ser «Don Manuel Joaquín Sanguino, alguazil mayor d’este Santo Oficio» (Img. 27). Aquest, a la recerca de Vicent Navarro, es desplaçà a Algemesí, després a Polinyà, a Sueca i, finalment, a Albalat de la Ribera, on el 22 de febrer aconseguí detenir l'acusat (Img. 30). El 23 de febrer, Navarro va ser encarcerat a la presó secreta de València.

Tres dies després, el 26 de febrer, el Tribunal va prendre la primera declaració a l'acusat. La Inquisició 


\title{
Jacob Mompó Navarro. La Inquisició de València contra Vicent Navarro (1750-1757), Diego Ramírez (1742) i Pedro Navarro (1588), tres casos de bestialisme
}

solia iniciar els primers interrogatoris als acusats preguntant-los si sospitaven per què havien sigut detinguts. Una de les respostes més freqüents, com la de Vicent Navarro, era que «no sabe, presume o sospecha la causa por qué ha sido preso» (Img. 67). Davant d'aquesta resposta, l'inquisidor advertí que:

En este Santo Oficio no se acostumbra prender persona alguna sin bastante información de aver dicho o hecho o visto hazer o decir [...] alguna cosa cuio conosimiento, punición y castigo toque al Santo Oficio, como es el delito de sodomia o bestialidad, conosiéndose hombres con hombres o con bestias [...] Assí, se le amonesta, recorra su memoria y diga la verdad; porque, asiéndolo así, abreviará su causa, y de no, se hará justicia (Img. 67-68).

Aquesta advertència de l'inquisidor deixava entreveure el delicte de què se l'acusava, això és, «sodomia o bestialidad». Així doncs, Vicent Navarro va recórrer a la memòria i va declarar que:

\begin{abstract}
Estando el declarante [...] en casa de Bautista Sala, y estando una burra de pelo pardo (su dueño, hermano de dicho Bautista Sala, vezino de la Vall, junto al convento de la Murta, que se llama Josep Sala) en la cavalleriza o establo de la propia casa de dicho su amo [...] conosió y se mescló carnalmente con dicha burra, metiendo su miembro viril por la natura de dicha burra, y que dicha mescla carnal y efusión de su semen fue solo una vez [...] y que dicho delito lo vio Bautista Sala (Img. 68).
\end{abstract}

Hem vist més amunt que les denúncies inicials apuntaven actes carnals de Navarro amb una egua i una gossa de perdius. L'acusat, però, com que desconeixia el contingut d'aquesta denúncia, va declarar un tercer delicte.

El 2 de març de 1750, el Tribunal, àvid d'una confessió de l'acusat sobre els altres dos delictes denunciats, demanava a Navarro que fes memòria. En aquell moment, el detingut va declarar l'accés carnal amb l'egua, durant el qual:

Estando el declarante en un campo plantado de moreras, en la partida del Camino de Alzira, término del lugar de Poliñá, se mescló, incluyendo y metiendo el declarante su miembro viril por el vaso y natura de una yegua tordilla propia de Bautista Sala, su dueño [...] Y que sólo fue una la ocasión en que cometió dicho pecado con dicha yegua. Y que derramó su semen fuera del vaso de dicha yegua, en tierra, pero no dentro del vaso de ella. Y que esto lo vio un hombre del lugar de Poliñá, no sabe su nombre ni apellido, solo sí, que estava arando en un campo inmediato al que travajava el declarante; y aora hase memoria que es pariente del tendero, y que vive cerca de la tienda, a unas tres casas de ella, en la calle dicha el Carrer Llarguet. (Img. 69-70).

Igualment va declarar l'afer amb la gossa de perdius:

Estando el declarante en el pajar de la casa de Bautista Sala, su amo, en el dicho lugar de Poliñá, en ocasión que estava una perra de perdices, manchada de blanco y negro, en dicho pajar, a otro día de san Sebastián, veynte y uno de enero próximo pasado, consintió el declarante e intentó meter sus partes viriles por el vaso de dicha perra perdiguera (Img. 70). 
Jacob Mompó Navarro. La Inquisició de València contra Vicent Navarro (1750-1757), Diego Ramírez (1742) i Pedro Navarro (1588), tres casos de bestialisme

En aquella ocasió, però, no va poder consumar l'acte perquè «estando para executarlo, lo vio Bautista sala y lo estorvó» (Img. 70).

Reunides totes les declaracions i ratificacions dels testimonis, el fiscal va emetre la seua acusació en què se'l considerava autor de tres delictes de bestialisme. Vicent Navarro va matisar els fets, tot afirmant que amb la gossa només va mantenir contactes carnals una vegada i no va poder consumar l'acte, i que, tant amb l'egua com amb la burra, només va passar una vegada i que "derramó su semen al sacar su miembro viril [...] en las vecindades de la natura de dicha burra" (Img. 80).

En canvi, per al fiscal: "parece inverosímil el que no hubiere tenido con dichos animales y bestias otros más excesos [...] Y que no aya derramado su semen dentro del vaso de dichos animales” (Img. 80).

El 23 d'abril de 1750, Francesc Pasqual Solsona, advocat i curador de Vicent Navarro, va presentar el seu escrit de defensa, on explicava que:

\begin{abstract}
Sin embargo de lo expuesto por el señor promotor fiscal en razón de las brutalidades que dexa executadas dicho menor, y confesadas en estos autos, se han de servir vuestras señorías, justicia mediante, usar con dicho menor de la piedad y comiseración que el Santo Oficio acostumbra con los buenos y arrepentidos confidentes [...] porque, constando por inspección de los propios autos, es inspección de dicho menor la rusticidad de su persona, ésta misma pulula la ignorancia de la simple privación y falta de ciencia y conocimiento del abominable delito de bestialidad (Img. 93).
\end{abstract}

Però més tard, el 12 de juny de 1750, els assessors i qualificadors del tribunal votaren quina hauria de ser, segons la seua opinió, la condemna de l'acusat. En aquest sentit, l'inquisidor Francisco Antonio Espinosa recomanava:

\footnotetext{
que este reo, en la sala del tribunal, a puertas abiertas, se le lea su sentencia sin méritos [...] Se le den 200 azotes por las calles públicas y acostumbradas de esta ciudad, y a que sirva 10 años en las minas del Almadén y a que pague las costas procesales (Img. 99).
}

El regent de la Reial Audiència, Antonio Azpérregui -autoritat seglar-, no va ser tan benigne com l'inquisidor i recomanava: "que en auto público de fe se lea su sentencia con méritos y sea relajado a la justicia y brazo seglar con confiscación de bienes" (Img. 99).

Les diferències entre aquestes dues possibles penes eren notables. Una sentència amb mèrits suposava haver de llegir, públicament, punt per punt, tots els capítols i testimonis del procés -per a major escarni de l'acusat- el dia de l'acte de fe. D'altra banda, relaxar el pres a la justícia seglar era un eufemisme que equivalia a la pena de mort a la foguera. En aquests casos, la Inquisició relaxava el condemnat a la justícia civil i aquesta s'encarregava d'executar-lo. 
Jacob Mompó Navarro. La Inquisició de València contra Vicent Navarro (1750-1757), Diego Ramírez (1742) i Pedro Navarro (1588), tres casos de bestialisme

Amb tot, la resolució final, una mica més benigna que les dues recomanacions anteriors, condemnava l'acusat a:
que en la sala del tribunal, a puertas abiertas, se le lea su sentencia sin méritos, y sirva por 4 años en las minas del Almadén, pagando las costas procesales. Y que antes sea encargado a persona docta y celosa, con quien por 8 dias haga unos ejercicios espirituales y confesión general (Img. 105-106).

El procés de fe, pròpiament dit, contra Vicent Navarro finalitza ací; però, el seu expedient conserva encara uns pocs documents més que ens aporten informació sobre les desventures que va viure anys després el nostre protagonista. En aquest sentit, l'1 de setembre de 1755, això són cinc anys després de la publicació de la sentència, Navarro va enviar una carta al Tribunal de la Inquisició de València en què explicava que, quan li van notificar la sentència, va ser empresonat en la Torre de Serrans. Després, va estar dos anys en les mines d'Almadén i d'allí va ser destinat a l'arsenal de Cartagena. Igualment explica que el compte enrere dels quatre anys de condemna que li pertocaven va començar el dia 20 d'agost de 1751 -per tant, havia estat més d'un any tancat a Serrans esperant a complir sentència- i, a hores d'ara -setembre de 1755-, continuava complint condemna encadenat als rems de la galera San José. Com que el temps de condemna havia exhaurit el 20 d'agost proppassat, demanava llicència inquisitorial perquè se'l posés en llibertat (Img. 109-111).

El 6 d'octubre enviava una altra carta demanant, de nou, la seua llibertat, i afegia que a l'arsenal de Cartagena havia passat «dos años amarrado a los remos y sin salir ha trabajado en dónde se halla» (Img. 113).

El Tribunal de València, reunit el 29 d'octubre de 1755, va acordar deixar-lo en llibertat (Img. 115), però la comunicació d'aquest acord no va eixir de València, direcció a Múrcia, fins al 5 de novembre d'aquell mateix any, segons s'explica en una comunicació posterior (Img. 119). Podem suposar que aquesta carta que havia de notificar al Tribunal de Múrcia la llibertat de Navarro no va arribar mai al seu destinatari, perquè el 16 d'octubre de 1756, un any després, Vicent Navarro va escriure una altra carta a la Inquisició de València suplicant, novament, per la seua llibertat (Img. 119). Al marge d'aquesta carta, un escrivà anotava que van rebre la petició de Navarro «en noviembre del año pasado de 1756». Una altra nota marginal en aquesta carta ordena: "Escrívase a la Inquisición de Murcia, acordándole lo que se le escrivió en 5 de noviembre de 1755” (Img. 119).

Vicent Navarro encara escriuria una altra carta més, el 19 de gener de 1757, en la qual demanava misericòrdia al tribunal inquisitorial, i explicava que, de la seua pena inicial, ja passaven 17 mesos:

Sin poder tener alivio ninguno en sus trabajos, estando amarrado noche i dia con dos gruesas cadenas a un banco de galera, con el poco alimento que la ración diaria ordena, y sin más amparo que el de Dios (Img. 121). 
Jacob Mompó Navarro. La Inquisició de València contra Vicent Navarro (1750-1757), Diego

Ramírez (1742) i Pedro Navarro (1588), tres casos de bestialisme

Aquesta carta no la va rebre la Inquisició de València fins al 25 de febrer de 1757. L'anotació marginal d'un escrivà del tribunal valencià indica que ja van escriure, en aquest mateix sentit, als inquisidors de Múrcia, el 5 de novembre de 1755 i el 16 de novembre de 1756. Ara, en febrer de 1757, tornarien a enviar a Múrcia la comunicació de la llibertat de Navarro (Img. 121). Finalment, el tribunal de Múrcia va respondre amb una carta en què explicava que ja havien deixat lliure Vicent Navarro el dia 28 d'abril de 1757 (Img. 123), això és, un any i huit mesos més tard del que li pertocava i set anys i un mes després d'haver sigut detingut a Albalat.

\section{Diego Ramírez, acusat de sodomia, hermafroditisme i bestialisme}

El segon cas de què ens ocupem és el de Diego Ramírez, ${ }^{6}$ teixidor, natural d’Abanilla (Múrcia). En el moment dels fets, l'any 1742, Ramírez residia a Molins, a tocar d'Oriola, on servia de criat d'Eustaqui Rocamora, marqués de Rafal i senyor de Molins. Diego Ramírez va ser acusat de bestialisme i sodomia, amb la particularitat que, segons alguns dels testimonis, l'acusat era hermafrodita. D'aquest procés, malauradament, únicament es conserven tres folis de les al legacions fiscals de Ramírez; documentació, no obstant això, suficient -en termes qualitatius- per entendre com es van desenvolupar els fets, tenint en compte que les al legacions fiscals contenen el resum, a grans trets, del seu procés. El document en qüestió s’inicia com segueix:

Esta sumaria se compone de 7 testigos. Los 2 primeros, singulares, del delito de bestialidad cometido por este reo, y dos, son formales del pecado nefando, y otros tres de que, siendo como es este reo ermafrodita, usa de ambos sexsos [sic], y que todos 3 tubieron acto consumado con el reo, usando éste del sexso femenino (Img. 1).

Els rumors sobre el suposat hermafroditisme de Diego Ramírez, segons sembla, estaven àmpliament estesos entre l'opinió pública de bona part dels oriolans d'aquella època. Podrem entreveure els motius d'aquests rumors més endavant, al llarg de les declaracions de l'acusat. Abans, però, el 7 de febrer de 1742, va declarar, per descàrrec de consciència, Sebastià Tomàs, mallorquí establert a Oriola:

El $1^{\circ}$ testigo del pecado de bestialidad de este reo es Sebastián Thomás, de nación mallorquín, de estado casado, vezino de Orihuela, de 31 años, el qual delató de su boluntad y por descargo de su consciencia, en 7 de febrero de este año de 742, diciendo que, siendo el reo ermafrodita, sabía usaba de ambos sexsos; así como haber oído a Joseph González, Mathías Alonso y Vicente Delfín, naturales y vezinos de aquella ciudad de Orihuela, que habían tenido parte con este reo por el sexso femenino; como también haberle oído a el testigo Tomás Sanz, vezino del lugar de Molins, haber visto que este reo tenía parte con un burro de Orán (Img. 1).

Fins aquest punt, Sebastià Tomàs ofereix testimoni d'oïdes sobre diversos rumors que ha sentit

6 AHN, Inquisició, 3725, exp. 123.

SCRIPTA, Revista internacional de literatura i cultura medieval i moderna, núm. 13 / juny 2019 / pp. 139 - 158 ISSN: $2340-4841 \cdot$ doi:10.7203/SCRIPTA.13.15478 


\title{
Jacob Mompó Navarro. La Inquisició de València contra Vicent Navarro (1750-1757), Diego Ramírez (1742) i Pedro Navarro (1588), tres casos de bestialisme
}

d'altres testimonis. Però la notícia sobre els actes pecaminosos de Diego Ramírez amb un ase va moure la curiositat del testimoni, el qual:

\begin{abstract}
Una de las noches del mes de junio próximo pasado, vio desde debajo de las ruedas de un coche dónde se escondió, que siendo como las 2 de la noche, este reo se fue dónde estaba el burraco atado, y desatándole, bajándose el reo de espaldas, subió el borrico encima de sí, con lo que dio crédito a lo que tenía oído y llebaba depuesto (Img. 1).
\end{abstract}

La praxi passiva de Ramírez és una mica peculiar en els casos de bestialisme, en què els acusats solen aparéixer a la documentació exercint l'acte de manera activa. D'aquesta particularitat esmentada en dóna fe el següent testimoni que hi apareix a la documentació, Tomàs Sans, qui, recordem, va donar notícia al primer testimoni sobre el gust de Ramírez envers la «sodomia bestial». Aquest testimoni:

\begin{abstract}
Natural y vezino del lugar de Molins, de 36 años, contesta en lo que es citado por el antecedente, diziendo que pocos días después de San Juan inmediato passado, habiendo ido Don Eustaquio Rocamora, señor de dicho lugar, con su familia a la casa que tiene en él, llevó por criado a este reo, el qual llebaba un borrico de Orán. Que al tiempo de ir el testigo a entrar en la bodega, que está inmediata a la cozina baja de dicha casa, con un brazado de hierba, adbirtió que este reo se había lebantado los calzones anchos que llebaba y, tomado el ramal del borriquillo y poniéndoselo por sobre el hombro, se subió el borrico sobre las espaldas, armado ya, y bolbiendo la mano el reo le cojió el miembro y se lo aplicó hacia sus partes; y bio que lo incluió dentro, deteniéndose como 3 Credos, los quales pasados, se bajó el borriquillo de sobre el reo, ya desarmado. Que por cuanto se dize de el reo que tiene de ambos sexos, no podía deponer ciertamente si fue por el preportero o por la parte muliebre, sólo sí que, por una u otra, fue consumado el acto (Img. 1-2).
\end{abstract}

El tercer dels testimonis conservats en aquestes al legacions fiscals és Vicent Delfín, de 17 anys i veí d’Oriola. Aquest:

Delató de sí y contra este reo en 8 de febrero de este año, diziendo que antes de las fiestas de Nabidad del año inmediato passado, siendo como a las 7 de la noche, lo llebó engañado este reo hacia la Peña, y entrándole hacia un callejón que está cerca de la cathedral, temeroso, el testigo echó a uir. Y agarrándolo el reo del brazo, lo condujo a espaldas de la casa del marqués de Rafal, dónde, desatacándose el reo, hiço ejecutase lo mismo este testigo. Y poniéndose el reo boca arriba, en postura de los pies en alto, le obligó a tener acto consumado por el baso preportero. Que diziéndole el deponente a el reo «Pícaro, que me has traído engañado», le respondió que también había engañado a otros (Img. 2).

El següent testimoni contra Diego Ramírez és Josep González, de 20 anys, sastre d'ofici, casat i habitant, igualment, d'Oriola. González va declarar per descàrrec de consciència:

En 6 de febrero de este año, diziendo que, iendo el declarante al convento de San Sebastián, de religiosas agustinas, extramuros de aquella ciudad, después de los días de Nabidad del año inmediato pasado, encontró a este reo, quien le dijo fuere con él y tendría cópula, para cuio 


\title{
Jacob Mompó Navarro. La Inquisició de València contra Vicent Navarro (1750-1757), Diego Ramírez (1742) i Pedro Navarro (1588), tres casos de bestialisme
}

\begin{abstract}
fin ya otras bezes había solizitado a el deponente, que, aunque con repugnancia, le siguió. Y llegando al conbento de san Agustín, se entraron en la cozina vieja de dicho conbento; y que, resistiéndose el declarante a el acto, por ser lugar sagrado, diziéndole el reo que no importaba, se arremangó los calzones anchos que llebaba. Y tendiéndose boca arriba, tubo parte y acto consumado con el reo por la naturaleza de muger, que tiene a la derecha de hombre. Que, aunque después lo había solizitado por lo mismo el reo, por 4 o 5 bezes, no había podido conbenzer a el testigo. Y que vio a el reo que también había tenido parte con Mathías Moreno, oficial de sastre (Img. 2-3).
\end{abstract}

Josep González, doncs, al llarg de la seua declaració, delata també a Maties Moreno. Aquest es converteix, al seu torn, en el següent testimoni en la causa contra Diego Ramírez. Segons Moreno:

\begin{abstract}
Con motibo de haber meses que oió ser el reo ermafrodita, mobido de curiosidad, encontrándole una noche que iba a moler trigo a el molino de aquella ciudad y diziéndole el reo que lo esperase, se apartaron a un lado del camino y tubieron acto consumado, sirbiendo el reo de muger por tener también naturaleza de tal, lo que reconozió mui bien ser cierto. Y que repitieron lo mismo en otra ocasión a la subida del sitio de San Miguel. Que era público en aquella ciudad entre la jente joben, que el reo solicita a innumerables, siendo de buen parezer. Y que le oió había tenido semejante cópula con Vizente Lillo (Img. 3).
\end{abstract}

Les delacions dels testimonis amplien la llista dels susceptibles a ser cridats per a declarar. Vicent Lillo, doncs, també declararà contra Diego Ramírez i, segons el seu testimoni:

\begin{abstract}
Sabiendo que este reo tenía de hombre y muger, mobido de curiosidad, tubo parte con él por la naturaleza de muger, siendo el acto consumado; y que le contó este reo en dicho lance que quando las fiestas de conclusión de [la] iglesia de Aspe, había tenido una gran noche porque más de 24 habían tenido parte con él (Img. 3).
\end{abstract}

El següent document que es conserva en aquest expedient fa referència a les declaracions de Diego Ramírez. A la pregunta habitual sobre si coneixia el motiu de la seua detenció, l'acusat va respondre que:

\footnotetext{
Presumía se le hubiese preso porque habría 3 meses que el probisor de Orihuela le puso en las cárceles episcopales porque los muchachos dieron en llamarle Diaguita, dando a entender que tenía de ambos sexos, de hombre y de muger. Y el fundamento que tubieron fue: que habría 4 meses que, pasando por dicha ciudad uno de los regimientos de infanteria que se embarcaron para Italia, le coxieron unos soldados, cuios nombres y el del regimiento ignoraba este reo, y emborrachándole lo sacaron fuera de la ciudad y tubieron parte con él por 3 vezes en 3 distinctas noches, sirviendo el reo de paciente, ignorando si esos actos fueron o no consumados por estar embriagado; solo sí que en la primera ocasión fue con penetración y lesión de su preportero. Que por haber referido el reo lo expresado a algunas personas, se esparzió la voz de que también tenía sexo de muger, y le puso preso dicho probisor. Pero, siendo falso, porque sólo tenía naturaleza de hombre, al cabo de dos meses le soltó de la prisión sin haberle echo cargo alguno, diciéndole saliese de aquel obispado; y que discurría haber sido preso por el Santo Oficio por haber faltado a lo que se le mandó por dicho probisor, acomodándose en Callosa, dónde fue preso (Img. 4).
} 


\title{
Jacob Mompó Navarro. La Inquisició de València contra Vicent Navarro (1750-1757), Diego Ramírez (1742) i Pedro Navarro (1588), tres casos de bestialisme
}

Així doncs, diversos testimonis afirmaren al llarg de les seues declaracions haver mantingut relacions sexuals amb Diego fent servir, a tal efecte, els suposats genitals femenins d'aquest; però l'acusat afirmava davant el Tribunal que no era pas hermafrodita. Davant d'aquesta disjuntiva:

\begin{abstract}
En vista de lo expressado, se mandó por el Tribunal que el médico y cirujano de él hiciesen inspección y reconocimiento de la persona del reo y declarasen lo que observasen en él en orden de su sexso. Resulta, declararon éstos, que habiendo practicado las más exactas diligencias para informarse de lo que se les mandaba, hallaban ser el reo varón perfectamente formado, sin seña alguna ni amago de la naturaleza o sexso de muger (Img. 4).
\end{abstract}

Però, per què els testimonis insistien a afirmar la condició d'hermafrodita de l'acusat? Al llarg de les seues declaracions, Diego Ramírez sembla donar resposta a aquest interrogant, tot afirmant que havia mantingut:

\begin{abstract}
actos sodomíticos consumados con barios hombres, que serían 20 vezinos de Orihuela, cuios nombres y apellidos ignoraba por no ser el reo de dicha ciudad; que en todos los dichos actos sodomíticos consumados hizo de paziente, con la postura de estar boca arriba con los pies lebantados en alto, por lo que era falso que a ninguno de los sugetos con qué sodomitaba le dijese que tenía naturaleza de muger, ni que tal fingiese el reo para atraer con más façilidad a los actos sodomíticos; porque, aunque era boz pública en Orihuela y se lo echaban en rostro muchas bezes, sería ocurrencia de los muchachos con quienes sodomitaba por la postura en que el reo se ponía (Img. 4-5).
\end{abstract}

Si, segons pareix, s'havia escampat per Oriola el rumor que Diego Ramírez era hermafrodita, sembla lògic pensar que els testimonis -acusats també de mantenir relacions amb Diego- utilitzaren aquest suposat tret fisonòmic com una mena d'atenuant. D'altra banda, l'acusat relacionava el rumor del seu suposat hermafroditisme directament amb la postura que solia adoptar durant les relacions sexuals que mantenia amb diversos individus. Tanmateix, i pel que fa als crims de bestialisme que se li imputaven:

Estubo el reo en esta audiencia absolutamente negatibo del delito de bestialidad de que le testifican 2 testigos formales y singulares, atribuiéndolo a la envidia de un cochero que tenía su amo, Don Eustacio Rocamora, llamado Sebastián de Tomás, que es el $1^{\circ}$ de dichos testigos. Y expresando que el no haber declarado, desde luego, sus culpas de sodomia era por creer que sólo había sido preso por ermafrodita, y por no saber las penas establecidas contra tan detestables delitos como los que llevaba confesados y en que había incurrido por su flaqueza (Img. 5).

Finalment, malgrat haver negat els delictes de bestialisme de què se l'acusava, en una audiència posterior:

Añadió el reo haberse acordado que por 8 o 10 bezes tubo el borriquillo de Orán actos de efusión de semen entre los muslos del reo, sin penetración del baso preportero del reo porque sí era doble; que el principio de dichos pecados bestiales incompletos fue que, habiendo 


\title{
Jacob Mompó Navarro. La Inquisició de València contra Vicent Navarro (1750-1757), Diego Ramírez (1742) i Pedro Navarro (1588), tres casos de bestialisme
}

\begin{abstract}
andado en zelo dicho pollino con otra de su especie, estando aún encendido, saltó enzima de los hombros del reo, y éste, llebado de su torpeza, se desatacó. Y bajándose los calzones consintió el que el burro arrojase su semen entre sus muslos. Y que en las demás ocasiones de efusiones fueron solicitadas por el reo haciendo que el pollino se encendiese con la de su especie; y antes de que se juntasen, solicitaba el reo que dicho pollino hiciese por entre sus muslos lo que con la burra. Y que esto no lo había confesado en las audiencias anteriores por el gran rubor y bergüenza que le causaba la fealdad de semejantes delitos, de los que estaba sumamente arrepentido (Img. 5).
\end{abstract}

El procés de Diego Ramírez, tal com hem dit, és peculiar per diversos motius. D’una banda, pel seu suposat hermafroditisme; d'altra, perquè a la documentació és poc freqüent trobar actes passius de bestialisme. De fet, dels 35 casos de bestialisme analitzats per Ruiz Astiz:

siempre son mencionados animales hembra, pues en ningún caso aparecen asnos, caballos o perros. Este hecho, sin duda, podría vincularse con el deseo de identificar la elección de tales animales con la de una supuesta mujer, o a que el acceso sexual sería más sencillo y satisfactorio con estas en vez de con los machos (Ruiz Astiz 2017: 312).

Però, segons els diferents testimonis del seu procés, Ramírez preferia adoptar un paper passiu durant els actes carnals amb animals mascles. És un fenomen aillat a la documentació, però cal tenir present que Ramírez, a més d'acusat de bestialisme, també ho va ser per mantenir relacions sexuals amb altres homes i, tal com hem vist, al llarg d'aquests accessos carnals l'acusat preferia sempre adoptar un paper passiu en la relació. Per tant, més que vincular l'elecció de l'animal amb una suposada dona, com suposa Ruiz Astiz per als casos que ha estudiat, en el cas de Diego Ramírez, aquest fet respondria a la tria d'un animal mascle amb qui pogués exercir un paper passiu d'acord amb els seus gustos sexuals personals.

\section{Pedro Navarro o Arbonés, acusat de bestialisme ${ }^{7}$}

El cas de Pedro Navarro presenta unes particularitats que convé d'explicar abans d'entrar en matèria. En primer lloc, tal com veurem, no està clara la identificació entre la persona de l'acusat, que afirma ser Pedro Arbonés, i la persona contra la qual testifica el testimoni principal d'aquest procés, que identifica l'acusat com a Pedro Navarro. D'altra banda, i a tall d'exemple, la portada de l'expedient identifica l'acusat amb el nom de: «Pedro Nabarro Narbonés, vezino de Fayón, junto a Mequinenza, en Aragón» (Img. 1), però la nota amb què els inquisidors demanen la captura de l'acusat, datada al palau de l'Aljaferia a 6 d'octubre de 1586, indica que es tracta de «Pedro Navarro, vezino del lugar de Villarluengo» (Img. 3). De fet, un document de 22 de desembre de $1586 \mathrm{amb}$ què s'indica al tribunal valencià la detenció de l'acusat, les primeres diligències del procés i el seu trasllat a València, indica que "a pareçido conveniente la dilaçión que a avido en tramitarlo por

7

5321, exp. 4.

AHN, Inquisició,

SCRIPTA, Revista internacional de literatura i cultura medieval i moderna, núm. 13 / juny 2019 / pp. 139 - 158

ISSN: $2340-4841 \cdot$ doi:10.7203/SCRIPTA.13.15478 
Jacob Mompó Navarro. La Inquisició de València contra Vicent Navarro (1750-1757), Diego Ramírez (1742) i Pedro Navarro (1588), tres casos de bestialisme

averse mudado el nombre y no estar çiertos si era el mesmo que el testigo dize” (Img. 5).

En segon lloc, la documentació apareix datada, bé a Saragossa, bé a València. Aquesta circumstància és producte de la divisió territorial dels diferents tribunals inquisitorials. En aquest sentit, malgrat que l'ordre de detenció s'emet des del palau de l'Aljaferia, a Saragossa, el suposat crim va ser comés a Rillo, Terol, i el testimoni principal va denunciar els fets a Cuevas de Cañart, territori situat sota dominis jurisdiccionals del Tribunal de València, que abastava la ciutat i l'arquebisbat de València, així com els bisbats de Tortosa, Sogorb, Albarrasí i Terol.

Sembla, doncs, que l'acusat era natural de Faió, tot i que en el moment dels fets, tant l'acusat com el denunciant, residien a Villarluengo. Amb tot, Pedro Navarro -o Arbonés- complementava els ingressos del seu ofici de paraire exercint de jornaler estacional, i per aquest motiu es desplaçava arreu del regne d'Aragó durant l'època de la sega. En aquest context, el 4 de setembre de 1586, a la localitat de Cuevas de Cañart (Terol), Domingo Corral va acusar Pedro Navarro del delicte de bestialisme (Img. 13-17). El 28 del mateix mes, el testimoni ratificava la seua deposició anterior:

\begin{abstract}
Apud villam de las Cuevas de Cañart, regni Aragonum, dentro en la casa y propia habitación del reverendo mossén Jaime de la Mata [...] comissario que és del Sancto Officio de la Inquisición en el presente reyno de Aragón [...] compareció personalmente constituido Domingo Corral, mancebo, vezino del lugar de Villarluengo [...] el qual dicho Domingo Corral, ante todas cosas, juró en poder y manos del dicho comissario, sobre la cruz y santos quatro Evangelios por él manualmente tocados y reverentemente adorados [...] dixo y deposó lo siguiente: que és de edad, este deposante, de veinte y tres años, poco más o menos, y que conoce muy bien a Pedro Navarro, mancebo, pelayre, por quanto ha estado y habitado en el dicho lugar de Villarluengo mucho tiempo y ha ido a segar en su compañía largos días. Y con esto dize que en el año más cerca passado de mil quinientos ochenta y cinco, yendo el deposante y el dicho Pedro Navarro a segar [...] llegaron a un pueblo que se llama Fraga. Y segando en aquél, en casa de uno llamado Pere Joan, llegó allí hun hombre pobre, el qual dixo conocía muy bien al dicho Pedro Navarro. Y se le engraçió y le dixo: «Vos sois Pedro Navarro, natural del lugar de Fayón». Y el dicho Pedro Navarro siempre negó y respondía que no sabía lo que se decía el dicho pobre hombre. El qual se allegó a este deposante y le dixo: «Amigo, ¿cómo vais en companyia de esse mal hombre que está huido de su tierra porque lo hallaron que cavalgava una mula?» (Img. 20-22).
\end{abstract}

Així doncs, Domingo Corral, mentre es trobava segant a Fraga, va fer amistat amb un personatge anònim, i aquest li va fer saber que Pedro Navarro era natural de Faió i que va fugir de la seua terra perquè l'havien trobat mantenint relacions sexuals amb una mula. L'advertència d'aquell segador desconegut, segurament, va despertar la curiositat de Domingo Corral. Aquest i l'acusat, el 4 d'agost de 1585:

llegaron los dos a un pueblo llamado Riello, de tierra de Teruel, y segando en una casa de uno llamado Pascual Navarro, una tarde, viniéndose del campo de segar a casa del amo, se adelantó el dicho Pedro Navarro y fue a un corral del dicho Pascual Navarro, el qual corral está junto con la casa del dicho Pascual Navarro. Y el dicho deposante, yendo a buscar al dicho Pedro Navarro, su compañero, lo alló y vio en el dicho corral. Y lo vio de cara, que estava junto a un 


\title{
Jacob Mompó Navarro. La Inquisició de València contra Vicent Navarro (1750-1757), Diego Ramírez (1742) i Pedro Navarro (1588), tres casos de bestialisme
}

\begin{abstract}
montón de fiemo y arrimado a una pared; y que vio claramente que tenía accesso carnal con una vaca, y sacar su miembro de la natura de la dicha vaca. Y azía los meneos del cuerpo por los quales el dicho deposante entendió claramente que el dicho Pedro Navarro tenía acceso carnal con dicha vaca. Y le vio sacar el miembro de la natura de dicha vaca y vio que quedó dicha natura de la vaca mojada (Img. 22-23).
\end{abstract}

El 16 de desembre de 1586, en el palau de l'Aljaferia de Saragossa, va comparéixer l'acusat. Aquest, a qui el testimoni anomenava Pedro Navarro:

\begin{abstract}
se dixo llamar Pedro Arbonés, natural del lugar de Fayón, junto a Mequinenza, en este reyno, hijo de Pedro Arbonés, labrador, vezino del dicho lugar de Fayón; de hedad que dixo ser de veynte y ocho años, y de oficio pelaire. Y que le prendieron en las Cuevas de Castellot, que no sabe si las llaman las Cuevas de Cañart, el juebes de la semana pasada; y entró preso en esta Aljafería el lunes d'esta semana, que se contaban diez del presente mes. Preguntado si sabe o sospecha la causa por qué ha sido preso y traído a las cárceles d'este Santo Officio, dixo que no lo sabe. Preguntado si éste se ha llamado por otro nombre en algún tiempo dixo que no le an llamado por otro nombre (Img. 47-48).
\end{abstract}

L'interrogatori inicial de la Inquisició aragonesa l'encaminava a respondre des de qüestions més generals, per exemple, si alguna vegada havia anat a segar, fins a d'altres més concretes com: «si seguó éste en un lugar que se llama Riello, en tierra de Teruel». L'acusat contesta afirmativament, tot precisant que va segar en aquella localitat de Terol l'any 1584. Però «preguntado si el agosto del año de ochenta y cinco segó éste en el dixo lugar de Riello, dixo que no» (Img. 48). Tot i això, el Tribunal demanava l'acusat que identificàs la gent amb què va anar a segar a la localitat de Rillo. Pedro Arbonés afirmava haver anat a segar «en companyia de unos foranos de Pitarque y de un hombre de Villarluengo que se llama Domingo Corral» (Img. 48).

Aquesta darrera resposta relacionava directament l'acusat amb el seu acusador. Les següents preguntes de l'interrogatori responien a l'afany dels inquisidors per saber més sobre la seua suposada relació sexual amb la vaca. No obstant això, Pedro Navarro, o Arbonés, va negar sistemàticament qualsevol accés carnal amb l'esmentat animal. El tribunal, doncs, preguntà a l'acusat per la seua trajectòria biogràfica a terres aragoneses. En aquest sentit, Arbonés va declarar:

\begin{abstract}
que en el dicho lugar de las Cuebas ha ocho meses qu está, y en Villarluengo ha residido dos años, y otros dos en la Cañada, y luego dixo que bien habrá residido seis años en los dichos lugares de Villarluengo y la Cañada, y que antes había residido más de año y medio en el lugar de Castellot, junto a las Cuebas. Y ha más de diez años que reside en lugares d'este reyno después que se bino de Catalunya ${ }^{8}$ (Img. 50-51).
\end{abstract}

El 19 de novembre, el fiscal utilitzava la declaració de l'únic testimoni d'aquest procés per

\footnotetext{
8 Suposem que es refereix al seu poble de naixement, Faió, municipi aragonés de la comarca del Matarranya, encara en zona lingüística catalana i tradicionalment adscrit a la diòcesi de Lleida.
}

SCRIPTA, Revista internacional de literatura i cultura medieval i moderna, núm. 13 / juny 2019 / pp. 139 - 158 


\section{Jacob Mompó Navarro. La Inquisició de València contra Vicent Navarro (1750-1757), Diego}

Ramírez (1742) i Pedro Navarro (1588), tres casos de bestialisme

confeccionar la seua acusació (Img. 53-54); malgrat que Pedro Arbonés va negar tots els fets, i també va negar, de nou, que el seu cognom fos Navarro.

Llavors, el 22 novembre, el Tribunal de Saragossa va ordenar el trasllat de persona i expedient al Tribunal de València perquè: "este reo cometió el delicto de que és acusado en el lugar de Riello, tierra de Teruel, districto y jurisdicción de la Inquisición de Valencia" (Img. 59). Per tal de traslladar el pres, el Tribunal aragonés "entregó la persona del dicho Pedro Navarro con un par de grillos en los pies a Pedro Beltran, carretero ordinario de esta çiudad a la de Valencia" (Img. 60).

Del 13 de febrer de 1587 és el primer document d'aquest procés redactat a València. Durant aquella audiència, hom demanava la

publicación de los testigos e provança que ay contra el dicho Pedro Navarro, alias Narbonés, declarándole los nombres [y] connombres de los testigos, día, mes e año en que testificaron, según uso y costumbre de semejantes negoçios (Img. 61-62).

El 21 de febrer de 1587, després d'escoltar les declaracions de l'únic testimoni, l'acusat

dixo que a la deposición del dicho Domingo Corral no se deve de dar fe assí por ser enemigo d'este y haver reñido con él en el lugar de Fraga; como porque en dicho lugar, dicho Corral le pidió ciertos dineros prestados y no se los quiso dar; y también porque es único y singular (Img. 65).

El següent document del procés de Pedro Navarro és del dia 25 d'agost de 1587. En aquella ocasió va ser l'acusat mateix qui va demanar audiència:

Dixo que la a pedido para dezir que él tiene por compañero de cárcel un morisco que está con grillos y con argolla, que se llama Agustín Moravit, el qual ha más de quinze días que le traxeron a la cárcel d'este y de Thomás Capucho, morisco. Y el dicho Agustín haxe la çalá cada noche, o las más noches, d'esta manera: que está reçando un rato en algaravía, e después alça y baxa la cabeça, tendidas las manos diziendo «Alaguavar». Y éste le pregunta que qué quiere dezir aquello. Y el dicho Agustín responde que el turco ama a Dios, e que él no cree que ay Espíritu Santo, ni hijo de Dios, ni madre de Dios. Y éste le dixo que sí creýa aquello. Y el dicho Agustín dixo qu él lo creýa como el turco, porque si no lo creyese, tanbién le mataría el turco.

Ítem dixo que 1 dicho Agustín, sintiendo que hablan en algunas cárçeles, les da bozes que guarden la ley de Mahoma. E que él quiere morir cabeça abaxo, como Mahoma. E que es alfaquí. E que tanbién sabía la ley de los judíos. Y éste le pregunto que qué sabía de la ley de los judíos, e le respondió que adoraban el Bobet.

Ítem dixo el dicho Agustín tres bezes que nuestra Señora, la Virgen Maria, hera mala, e que un judío avía tenido parte con ella, y que todavía quiere morir como perro moro. E oy dixo que hera captivo del Gran Turco. E que tanbién a dicho que haze del loco porque le suelten, e por más que le hechen fierros, a de boçear más. Y qu este a hablado e dicho a mí que 1 dicho Thomàs Capucho sí entendía al dicho Agustín, el qual le respondió que no. E quando ponen esposas e açotan al dicho Agustín Moaravit, le sabe mal al dicho Capucho, diziendo que le suelten allà fuera e le den una espada e berán si, aunque sean diez hombres, se defenderá d’ellos (Img. 67-69). 
Jacob Mompó Navarro. La Inquisició de València contra Vicent Navarro (1750-1757), Diego Ramírez (1742) i Pedro Navarro (1588), tres casos de bestialisme

Durant l'audiència del 25 de gener de 1588, l'acusat seguia negant-ho tot. Llavors, la Inquisició va ordenar l'aplicació del turment per tal d'obtenir la confessió del reu:

\begin{abstract}
Fallamos, attento los autos y méritos d'este processo, indicios y sospechas que d'él resultan contra el dicho Pedro Navarro, alias Narbonés, que le devemos de condenar y condenamos a que sea puesto a qüestión de tormento, en el qual, éste persevere tanto tiempo quanto a nós bien visto fuere para que en él diga la verdad; con protestación que le hazemos que, si en dicho tormento muriere, fuere lisiado o se le siguiere mutilaçión de miembro o effusión de sangre, sea a su culpa y cargo, y no a la nuestra, por no aver querido dezir la verdad (Img. 78).
\end{abstract}

En veure aquesta sentència de turment, l'acusat va respondre que "no porque un bellaco le acuse falsamente le an de despedaçar en tormento, porque el que le acusa a reñido con éste e, por no se poder bengar, le a puesto en esta maldad" (Img. 79). Però malgrat les queixes de Pedro Arbonés, "fue mandado baxar a la cámara del tormento, donde fueron e baxaron los dichos señores inquisidores. Y estando en la cámara del tormento, fue amonestado que diga la verdad y no se quiera ver tan baxo; donde no, que se executarà el tormento" (Img. 79). Ara bé, davant les amenaces dels inquisidors, la resposta d'Arbones va ser clara: "Dixo que no ha de dezir lo que no ha hecho, que si lo uviera hecho, desde la primera vez lo uviera dicho" (Img. 79). Tanmateix, aquesta resposta no va satisfer el desig inquisitorial, atés que «Fue amonestado que diga la verdad; donde no, que le mandaran desnudar» (Img. 79). Però l'acusat, lluny d'acceptar com a vertaderes les declaracions del testimoni, "dixo que no tiene más que dezir, que se tiene a los primeros dichos, que él se llama Pedro Narbonés” (Img. 79).

Reproduïm tot seguit les anotacions referents a aquella sessió de turment:

Fue mandado desnudar. Y estándose desnudando dixo que, pues él a hecho nada, que el que le acusa lo pagarà e darà qüenta a Dios que lo ve todo e nada se le enzierra.

Y estando desnudo fue amonestado que diga la verdad; donde no, que le mandaran ligar y atar a la garrucha.

Dixo que no tiene qué dezir, que más quiere morir en la fe de Jesucristo que no dezir lo que no ha hecho. Que una bez puede morir, que no a de morir dos vezes.

Fuele dicho que ya está amonestado que si muriere sea por su qüenta e culpa, que solamente se le pide dezir e declarar la verdad.

Dixo que no tiene temor de que Dios le de culpa en esto, triste del que le acusa falsamente.

Fue mandado ligar e atar a la garrucha. Y estándole atando, dico que no ha de condenarse por dezir lo que no ha hecho.

Fue amonestado que diga la verdad; donde no, que le subirán la garrucha arriba.

Dixo: «Muy ilustres señores, no tengo qué dezir».

Fue mandado subir la garrucha arriba. E subiéndole, callava e no se quexava. Y estando en alto començó a quexarse, e dezia bozes: «Bia fora! Bia fora!».

Y estando en alto la garrucha, fue amonestado que diga la verdad.

Dixo que no tiene más que dezir: «Báxenme».

Fuele dicho si quiere dezir la verdad.

Dixo: «No tengo qué dezir». 


\section{Jacob Mompó Navarro. La Inquisició de València contra Vicent Navarro (1750-1757), Diego Ramírez (1742) i Pedro Navarro (1588), tres casos de bestialisme}

Fue mandado baxar, aviendo estado en alto dos Misereres. Y estando abaxo y sentado en el banquillo, fue amonestado que diga la verdad ahora qu está abaxo, pues tiene dicho que le baxen. Dixo que por un bellaco le an de despedaçar.

Fue amonestado que diga la verdad, pues que está quieto y sosegado, antes que se vea en más trabaxo. Dixo que no tiene qué dezir.

Fue amonestado que diga la verdad; donde no, que le subirán la garrucha arriba.

Dixo que no tiene qué dezir, muy ilustre señor, que si lo huviera hecho, él se viniera a presentar. Que quando le traían de Çaragossa, no benía preso ni le ponían en cárçeles.

Fue mandado subir la garrucha arriba. Y estando subido, dava bozes. E dixo: «No tengo qué dezir», y calló. E luego dixo: «Sacratíssima reyna de los ángeles, ansý como vós sois misericordiosa, ansí me ayudéis, reyna de los ángeles, bós me queráis favorecer».

Y estando en alto dos Misereres, le fue dicho que le baxarán, si quiere dezir la verdad.

Dixo que no tiene qué dezir.

Fue mandado baxar e sentar en el banquillo. Y estando abaxo e sentado, fue amonestado que diga la verdad, ahora qu está sin tormento e sin pena.

Dixo que no a de dezir lo que no a hecho

Fue amonestado que diga la verdad; donde no, que le mandarán atar la piedra pequeña a los pies.

Dixo que no tiene qué dezir.

Fue mandado atarle la piedra pequeña a los pies.

Dixo que Dios se lo demande. Y estándole atando la piedra dixo que an de hazer dezir lo que no ha hecho.

Fue amonestado que diga la verdad; donde no, que le mandarán subir la garrucha arriba.

Dixo que no tiene qué dezir.

Fue mandado subir con la piedra la garrucha arriba; y subiéndole, callava y no dezía nada. Y estando arriba fue amonestado que diga la verdad e no se quiera ver en trabaxo.

Dixo que no a de dezir lo que no a hecho, «iNuestra Señora de Monserrate!».

Fuele dicho que si quiere dezir la verdad, que le baxarán, e no se quiera ver en peligro.

Dixo que no tiene qué dezir.

Fue mandado baxar, e baxándole se quexava; y esto aviendo estado en alto dos Misereres. Y estando abaxo e sentado en el banquillo, le fue dicho que no se quiera ver en trabaxo, antes que se agrave el tormento, pues está ahora sosegado e sin él.

Dixo que no tiene qué dezir.

Fue amonestado que diga la verdad; donde no, que le mandarán subir la garrucha arriba.

Dixo que por fuerça a de dezir lo que no a hecho.

Fuele dicho que no por fuerça diga lo que no a hecho, sino que diga la verdad.

Dixo que pues no lo a hecho, no a de dezirlo, que Dios le ayudará.

Fue mandado subir la garrucha arriba. Y subiéndole dixo que no tenía qué dezir. Y estando en alto fue amonestado que diga la verdad; donde no, que se proseguirá el tormento.

Dixo que no tiene qué dezir.

Fue mandado baxar aviendo estado en alto dos Misereres. Fue sentado en el banquillo. Y estando sentado, fue amonestado que diga la verdad; donde no, que se proseguirá el tormento. Dixo que no tiene qué dezir.

Y luego, los dichos señores inquisidores e ordinario, por ser tarde, mandaron suspender el tormento, con protestaçión que no le davan por suffiçientemente atormentado, e se reservavan ansí de le tornar a continuar (Img. 79-86).

Malgrat la duresa de la sessió de turment, durant l'audiència del 29 de gener de 1588, l'acusat va tornar a negar punt per punt cadascun dels delictes de què se l'acusava (Img. 86-87). Així doncs, 
Jacob Mompó Navarro. La Inquisició de València contra Vicent Navarro (1750-1757), Diego Ramírez (1742) i Pedro Navarro (1588), tres casos de bestialisme

davant la negativa de l'acusat a declarar els seus delictes, el 6 de febrer de 1588 el Tribunal de València va emetre la seua sentència definitiva, segons la qual:

Fallamos que devemos de mandar e mandamos a la persona de Pedro Narbones Navarro que sea desterrado y le desterramos de todo el districto de esta Inquisición por tiempo y espacio de tres años; e no lo quebrante ni entre en nuestro districto por el dicho tiempo, so pena de tres años de galeras. E más le condenamos en las costas d'este processo (Img. 91).

El dia 8 d'aquell mateix mes, la Inquisició va comunicar al pres el resultat de la sentència, que el reu va acceptar de complir. Malgrat tot, va aprofitar aquella audiència per a donar notícia d'uns comentaris que havia sentit durant la seua reclusió:

Bien se acuerda aber oydo hablar de noche los presos unos con otros. Y que, entre otros, a oydo dezir a Miguel Conde que bevería de la sangre del alcaide, que le quiere mal. Y que a otros presos les ha oydo dezir que le quieren mal porque él husa grillos sintiéndoles hablar. E que el alcayde le ha tratado bien y no sabe que quieran hacelle daño (Img. 93-94).

L'alcaid a què es refereix Arbonés era Andrés de Castro. Es tracta del mateix alcaid que apareix al procés de fe d'Amador de Molina (1588), procés que ja vam treballar anteriorment (Mompó 2018). A jutjar per la consulta creuada de fonts, l'amenaça que, segons Pedro Arbonés, planava sobre Andrés de Castro era certa. En aquest sentit, el Libr segundo de méritos de reos penitenciados del Tribunal de Valencia ${ }^{9}$ conté la següent súplica de l'alcaid:

\begin{abstract}
Andrés de Castro, alcayde de la Inquisición de Valencia, ha más de dos meses que está malo en la cama y, siendo de Dios servido que ba mejorando, yendo a las diez de la noche visitando las cárçeles, teniendo yntençión d'él matar un preso, y teniendo arrancados muchos ladrillos para ello, al tiempo que yba a entrar por la puerta, le tiró uno, con el qual le dio en la boca y le derrivó dos dientes y le hirió en la cara; de manera que agora está con grande peligro de su vida, como podrán ynformar los ynquisidores. Y como su officio sea de tan poco salario y sus hijos muchos y la enfermedad tan larga, padeçe extrema neçesidad y travajo. Por tanto, supplica humilmete a vuestra alteza sea servido hazerle merced de alguna ayuda de costa. Y en ello espera de vuestra alteza serviçio a Dios y a ste supplicante, grande merced y limosna, porque, entre los hijos que tiene, ay tres hijas donzellas para casar (AHN, Inq., L. 934: 118r).
\end{abstract}

Més enllà de les particularitats d'aquest procés, la consulta creuada de fonts documentals pot resultar un instrument d'allò més útil per tal de comprendre les circumstàncies comunes i quotidianes de personatges marginals com Vicent Navarro, Diego Ramírez, Pedro Arbonés o, també, de personatges secundaris dels processos, com el mateix alcaid Andrés de Castro.

9 AHN, Inquisició, Llibre 934. 
Jacob Mompó Navarro. La Inquisició de València contra Vicent Navarro (1750-1757), Diego

Ramírez (1742) i Pedro Navarro (1588), tres casos de bestialisme

\section{Bibliografia}

Abad, Jose Maria \& García, Juan Manuel (1999) «Un proceso penal por bestialismo en el siglo Xviı: el caso del ciudadano francés Juan de la Liset en la villa de Yunquera de Henares (Guadalajara)», Boletin jurídico de la Universidad Europea de Madrid, 2 pp. 1-18.

Bazán, Iñaki (2007) «La construcción del discurso homofóbico en la Europa cristiana medieval», En la España Medieval, 30, pp. 433-454.

Martínez Sanz, Fortunato (2016) «Pleito litigado por Juan de Castillar contra Juan de Atienza, vecinos de Tortuera (Guadalajara), sobre acusación de bestialismo, resuelto en última instancia en la Real Chancillería de Valladolid, junio de 1497», Boletín ANABAD, LxvI: 2, pp. 193-200.

Masferrer, Aniceto (2017) «La distinción entre delito y pecado en la tradición penal bajomedieval», AHDE, LXXXVII, pp. 693-756.

Molina, Fernanda (2010) «La herejización de la sodomía en la sociedad moderna. Consideraciones teológicas y praxis inquisitorial», Hispania Sacra, LXII, pp. 539-562.

- (2014) «Femina cum femina. Controversias teológicas, jurídicas y médicas en torno a la sodomía femenina en el mundo hispano (Siglos XVI-XVII)», Arenal, 21: 1 pp. 153-176.

Mompó, Jacob (2018) «El procés contra el mulat Amador de Molina per sodomia, del 1588», SCRIPTA, Revista internacional de literatura i cultura medieval i moderna, 12, pp. 34-70.

Montero, Emilio (2010) «La sexualidad medieval en sus manifestaciones lingüísticas: pecado, delito y algo más», Clio \& Crimen, 7, pp. 41-58.

Motis Dolader, Miguel Ángel (2000) «Imago Dei deturpatur: El pecado "nefando" o "contra natura" en el Arzobispado de Zaragoza (Siglos XV-XVI)», Hispania Sacra, 52: 105, pp. 343-365.

Riera i Sans, Jaume (2014) Sodomites catalans. Història i vida (segles XIII-XVIII). Barcelona, Editorial Base.

Ruiz Astiz, Javier (2017) «"Meresce la pena ordinaria de muerte”: Estudio de las denuncias por bestialismo en la Navarra del Antiguo Régimen», Chronica Nova, 43, pp. 299-333.

Tomas y Valiente, Francisco (1990) «El crimen y pecado contra natura», Francisco Tomás y Valiente et al. (eds.), Sexo barroco y otras transgresiones premodernas. Madrid, Alianza Editorial, pp. 33-56. 